\title{
Management of extensive intraparotid vascular malformation: a case report
}

\author{
Katerina Anesti ${ }^{1}$, Zachary Moaveni' ${ }^{2}$, Heng-Yi Wu ${ }^{3}$ \\ ${ }^{1}$ Department of Plastic and Reconstructive Surgery, St. Andrew's Centre, Chelmsford, UK. \\ ${ }^{2}$ Department of Plastic and Reconstructive Surgery, Counties Manukau DHB, New Zealand. \\ ${ }^{3}$ Waikato District Health Board, Private Bag 3200, Hamilton 3240, New Zealand.
}

Address for correspondence: Miss. Katerina Anesti, Department of Plastic and Reconstructive Surgery, St. Andrew's Centre, Chelmsford, UK. E-mail: katanest@gmail.com

\begin{abstract}
Treatment of large soft tissue vascular lesions remains one of the greatest challenges in modern plastic surgery. The extent of the disease and the involved structures, but also the expectations of the patients are important in determining the way of treatment. The effective management of hemangiomas and vascular malformations of the head and neck requires a team approach, in order to understand the biologic behavior of the lesion, complete the diagnostic studies necessary to define the area of involvement, and understand the benefits and limitations of interventional radiologic and surgical procedures. The synthesis of this knowledge can help determine the best treatment. The strategic plan and subsequent management of a 34-year-old Maori man with an extensive arteriovenous intraparotid malformation is presented.
\end{abstract}

Key words:

Embolization, hemangiomas and vascular malformations, intraparotid malformation, vascular lesions

\section{INTRODUCTION}

Treatment of large soft tissue vascular lesions remains one of the greatest challenges in modern plastic surgery. The extent of the disease and the involved structures, but also the expectations of the patients are important in determining the way of treatment. ${ }^{[1]}$

The biologic classification of hemangiomas and vascular malformations (VMs) by Mulliken and Glowacki in the early 1980s has not only simplified the terminology, but has also clarified their clinical behavior and treatment options. ${ }^{[2]}$ In most instances, a hemangioma can be differentiated from a VM by the history. ${ }^{[3]}$

\begin{tabular}{|l|l|}
\hline \multicolumn{2}{|c|}{ Access this article online } \\
\hline Quick Response Code: & Website: \\
\hline & www.parjournal.net \\
\cline { 2 - 2 } & \\
\hline
\end{tabular}

\section{CASE REPORT}

A 34-year-old Maori man presented with an extensive arteriovenous malformation over his left face. The patient first noted small cherry-sized nodules behind his left ear at 8 years of age. His main symptom was recurrent and spontaneous bleeding, which he controlled with direct pressure. The lesion remained quiescent until 10 years later, when he noticed progressive enlargement of the mass. In addition to the frequent bleeding, he began experiencing increasing pain, skin tightness and troublesome pulsation at night [Figures 1-3]. The patient agreed to publish his facial pictures and signed the form.

Magnetic resonance imaging (MRI) demonstrated a large VM, which predominantly filled the superficial aspect of the left parotid gland and extended posteriorly into the left external ear [Figure 4]. Its blood supply was derived from the left external carotid artery [Figure 5].

In preparation for surgical resection, patient underwent embolization 1 week prior to operation. The left occipital artery was embolized with 3 Guglielmi Detachable Coils (Target Therapeutics, Fremont, California, USA) and 
the superficial temporal artery with Onyx Liquid Embolic System (Onyx ${ }^{\circledR}$ HD-500) [Figure 6]..$^{[4,5]}$ This resulted in reduction in lesion size and its vascularity. The planned excision included the skin directly overlying the parotid as well as the lower half of the ear [Figure 7] and extended down into the neck, to allow for closure of the defect as a cervicofacial rotation advancement flap. Careful dissection allowed for retrograde identification of the facial nerve branches. The tumor was circumscribed and simultaneous dissection performed in all directions [Figure 8]. It was possible through this approach to then remove the entire tumor superficial and deep to the facial nerve, including the lower part of the ear [Figures 9 and 10]. It was decided at the end of the procedure not to remove the remaining components of the pinna as these are quite asymptomatic and removing them wound mean probably having to use a temporal parietal fascia and covering it with a skin graft, which is considered unnecessary at present. However,

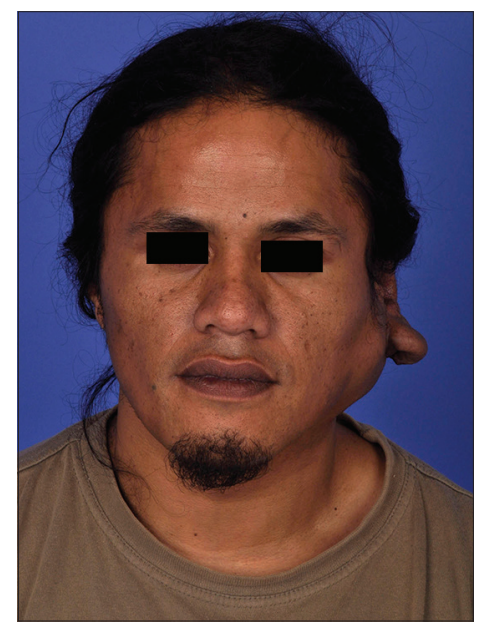

Figure 1: Preoperative anteroposterior view of the patient with large vascular malformation. A $6 \mathrm{~cm}$ by $8 \mathrm{~cm}$ pulsatile mass over the left parotid region, down to the angle of the jaw, and involving the left earlobe with resultant macrotia, with multiple raised nodules form underlying ectatic vessels are seen throughout. The overlying skin is discolored and taut

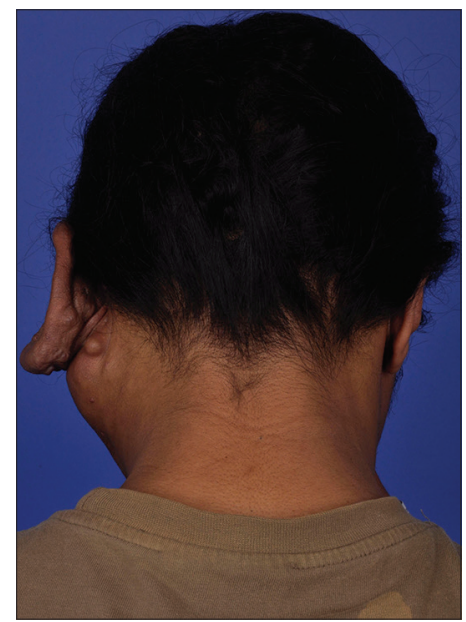

Figure 3: Posterior view this would be an easy procedure to do as a second stage should the pinna component become problematic.

There were no complications related to either the preoperative angiography or embolization procedure. The patient was discharged on day 5 after the procedure. Histology confirmed arteriovenous malformation involving the subcutaneous tissue and parotid gland without any atypia or malignancy present. There has been no recurrence to our knowledge so far.

\section{DISCUSSION}

Maxillofacial VMs are formed due to an error of vascular morphogenesis. They may correspond to a defective remodeling process at the final stages of vessel formation. Although no hereditary VM exist, the defect might be genetically based and secondarily expressed in the first few years of life. VM generally grow in proportion to the growth of the affected child, but may increase in size secondary to various triggering factors such as increased

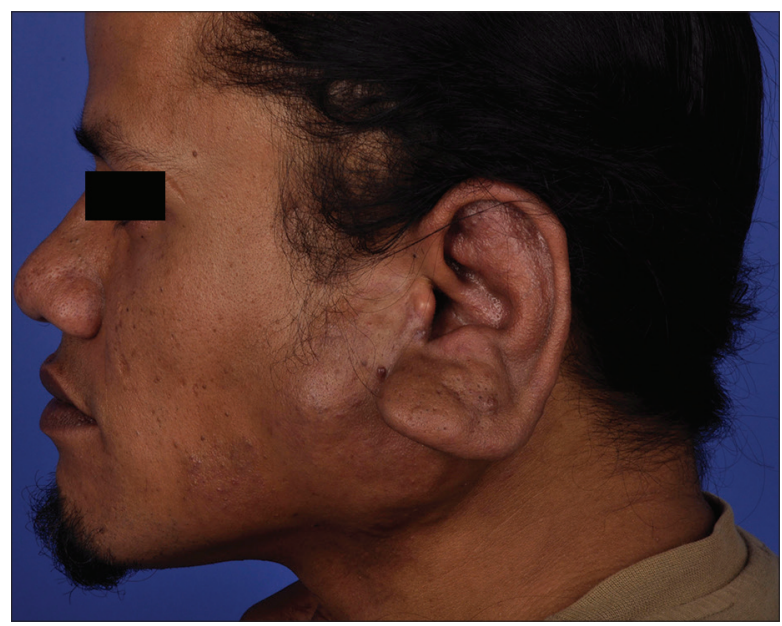

Figure 2: Lateral view of the same patient

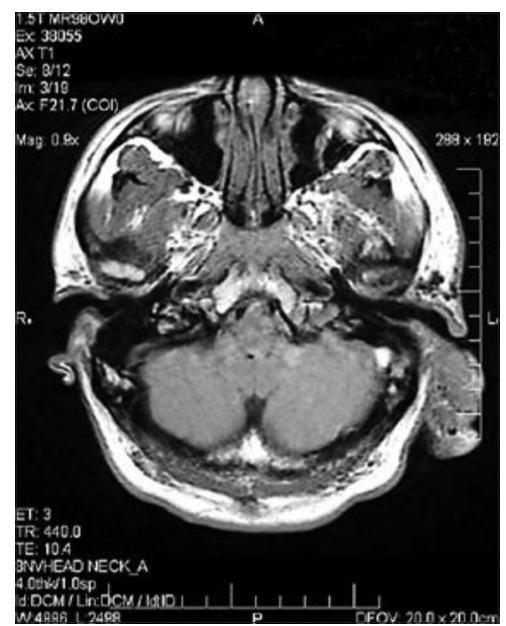

Figure 4: Magnetic resonance imaging confirmed the presence of a vascular malformation of the left external carotid artery supplying in and around the scalp and the left ear 


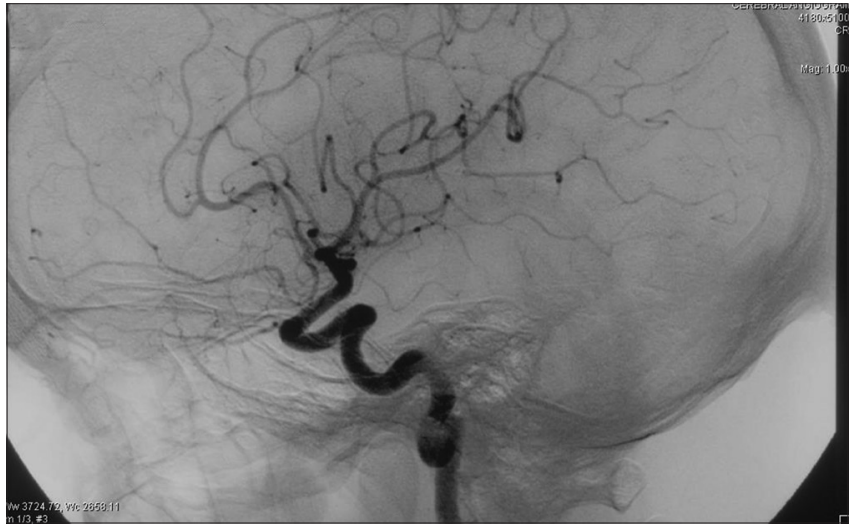

Figure 5: Digital subtraction angiography identified an arteriovenous malformation around the left ear

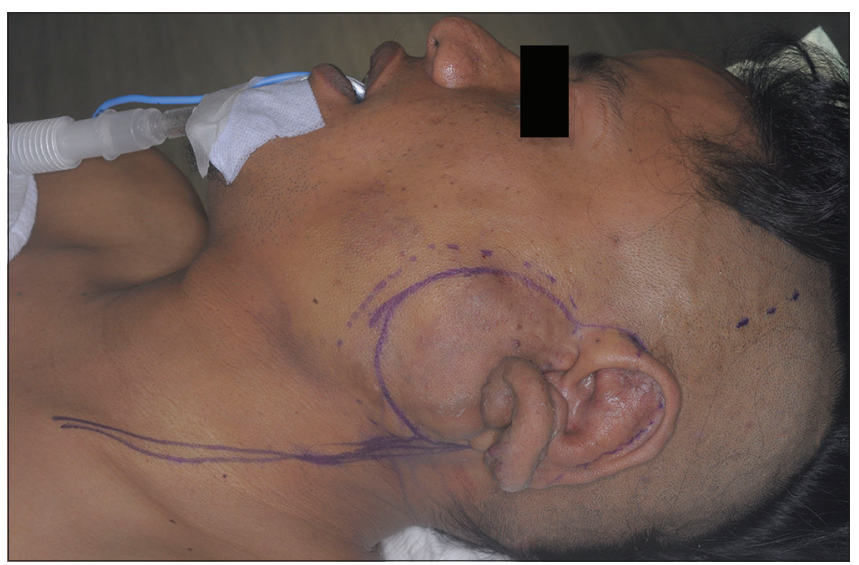

Figure 7: Preoperative design and marking of the cervicofacial rotation flap

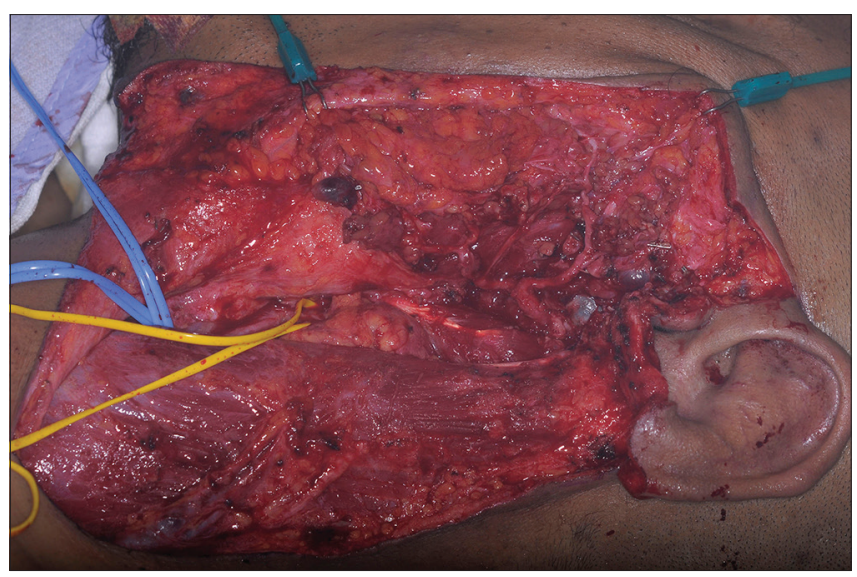

Figure 9: Intraoperative view following excision of the vascular malformation

blood flow, arterial occlusion and venous thrombosis, endocrine, trauma, or iatrogenic insults such as incomplete surgery and proximal embolization, and infection.

High flow in an existing VM can induce arteriovenous shunting, which, in turn, increases flow demand, cascading enlargement of the malformation.

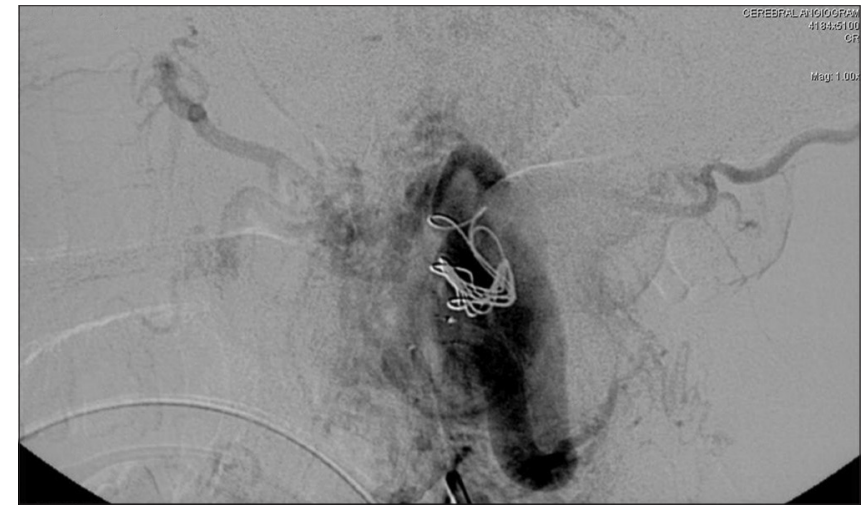

Figure 6: Digital subtraction angiography postembolization: The hypertrophic left occipital artery feeding the main A-V fistula was occluded by 3 Guglielmi Detachable Coils (Target Therapeutics, Fremont, California, USA). Anterior auricular artery branches supplying the vascular nidus was embolized with Onyx Liquid Embolic System (Onyx ${ }^{\circledR}$ HD-500)

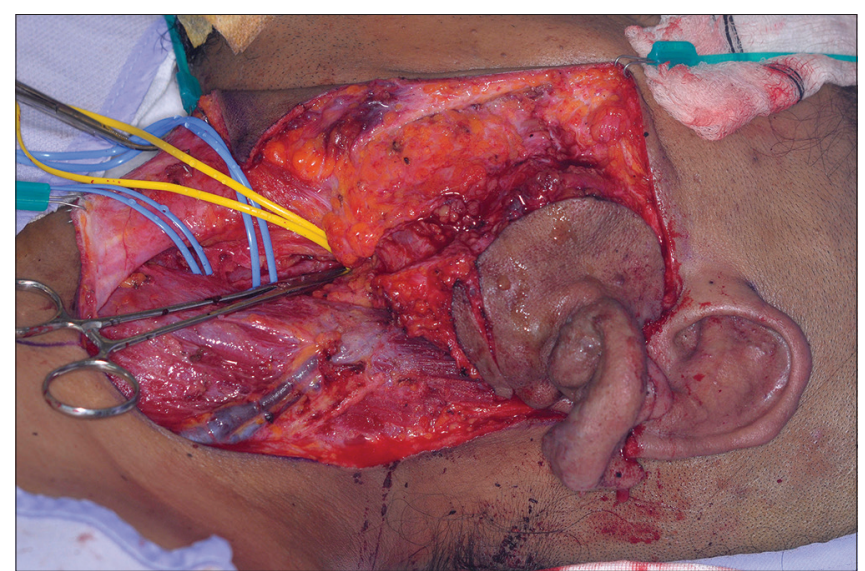

Figure 8: Intraoperative view after careful dissection of the facial nerve and control of the neck vessels

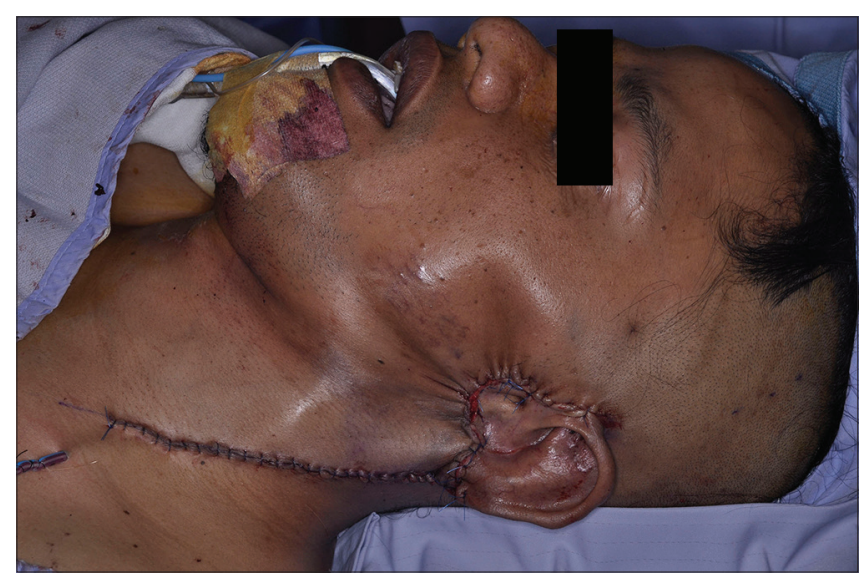

Figure 10: Postoperative view after skin closure

Increased understanding of these additional physiologic variants may help to define their clinical presentation and evolution and assist in designing therapeutic strategies. ${ }^{[6]}$ The diagnosis is usually made based on clinical history and physical examination. Cross section 
noninvasive imaging such as computed tomography (CT) or MRI is helpful for assessment of the extent of the disease, associated lesions, or multifocal involvement. MRI is the most useful single imaging modality in the investigation of VMs. The combination of multiplanar spin echo imaging and flow-sensitive sequences permits characterization of the nature and extent of most lesions. Angiography is reserved for patients in whom a decision has been made to intervene and is generally performed at the same time as embolization. VM are challenging to treat and require the skills of multiple disciplines.

Management of these lesions is best achieved by a specialist who understands the various clinical expressions of the problem, the natural history of the lesion, and the patient's needs. The primary goal of treatment is to restore and preserve function, stop bleeding, and improve or restore cosmesis.

Vascular malformation in children under 10 years of age may interfere with natural growth and maturation of the maxillomandibular frame, causing malocclusion of the mouth or modeling defects owing to external pressure on the forming bones or sinuses. Early intervention can arrest or even reverse such changes. ${ }^{[6]}$

The use of sclerosing and/or embolic agents in the treatment of hemagiomas was first described by Brooks in $1931,,^{[7]}$ documented by Edgerton in 1976..$^{[8]}$ Since then, preoperative embolization of soft tissue vascular lesions became almost the standard of care in the surgical management of these lesions.

The selection of an appropriate agent depends on the type of lesion, the method of embolization, and the experience of the interventional radiologist. The embolization procedure not only decreases the operative bleeding, but also facilitates the identification of a safe tissue plane for surgical excision.

Total resection is the gold standard. Three-dimensional (3D) CT scans facilitate both a better understanding of their complex 3D configuration and their relations with other anatomic structures such as bones and vessels. In addition, postoperative visualization demonstrates the volume of tissue removed. ${ }^{[9]}$ Conventional imaging modalities, such as MRI and angiography, are good for understanding both the extent and the flow characteristics of the disease.

\section{CONCLUSION}

Effective management of hemangiomas and VMs of the head and neck requires a team approach, in order to understand the biologic behavior of the lesion, complete the diagnostic studies necessary to define the area of involvement, and understand the benefits and limitations of interventional radiologic ${ }^{[10]}$ and surgical procedures. The synthesis of this knowledge can help determine the best treatment. ${ }^{[1]}$

\section{REFERENCES}

I. Eivazi B,Werner JA. Venous and arteriovenous malformations in the head and neck region. Therapeutic options and challenges. HNO 2014;62:19-24.

2. Mulliken JB, Glowacki J. Hemangiomas and vascular malformations in infants and children:A classification based on endothelial characteristics. Plast Reconstr Surg 1982;69:412-22.

3. Burns AJ, Navarro JA, Cooner RD. Classification of vascular anomalies and the comprehensive treatment of hemangiomas. Plast Reconstr Surg 2009; |24:69e-8|.

4. Guglielmi G, Viñuela F, Sepetka I, Macellari V. Electrothrombosis of saccular aneurysms via endovascular approach. Part I:Electrochemical basis, technique, and experimental results.J Neurosurg 1991;75:1-7.

5. Guglielmi G,Viñuela F, Dion J, Duckwiler G. Electrothrombosis of saccular aneurysms via endovascular approach. Part 2: Preliminary clinical experience. J Neurosurg 1991;75:8-14.

6. Niimi Y, Song JK, Berenstein A. Current endovascular management of maxillofacial vascular malformations. Neuroimaging Clin NAm 2007; 17:223-37.

7. Brooks BL. Discussion: Noland and Taylor. Trans South Surg Assoc 1931;43:176.

8. Edgerton MT.The treatment of hemangiomas:With special reference to the role of steroid therapy. Ann Surg 1976;183:517-32

9. Konas E, Canter HI, Cil B, Peynircioglu B, Karabulut E, Tuncbilek G, Kayikcioglu A, Erk Y. Volumetric assessment of results of treatment of vascular malformations of the head and neck regions treated with a minimally invasive surgical technique after embolization procedure. J Craniofac Surg 2009;20:402-5

10. Dmytriw AA, Ter Brugge KG, Krings T, Agid R. Endovascular treatment of head and neck arteriovenous malformations. Neuroradiology 20।4;56:227-36.

II. Yadav P, De Castro DK,Waner M, Meyer L, Fay A.Vascular anomalies of the head and neck:A review of genetics. Semin Ophthalmol 20I3;28:257-66.

How to cite this article: Anesti $\mathrm{K}$, Moaveni $\mathrm{Z}$, Wu HY. Management of extensive intraparotid vascular malformation: a case report. Plast Aesthet Res 2014;1:33-6.

Source of Support: Nil, Conflict of Interest: None declared.

Received: 11-03-2014; Accepted: 03-05-2014 